\title{
Nonbook Materials in a Teachers College Library ${ }^{1}$
}

Miss Grady is librarian, Ball State Teachers College, Muncie, Ind.

T HE TEACHERs college, presumably, is an 1 institution of higher learning in which those enrolled are provided with such training and experience as will contribute to their future performance as teachers in a chosen field. What this contribution is must depend on the nature of the institution-its physical equipment, its material resources, its faculty, and its administrative philosophy and leadership in developing a closely coordinated program. It seems safe to conclude that, given intelligent students, the excellence of the product will vary in direct relationship with the excellence of the institution as a whole.

The preceding statements have general acceptance. It is probable, furthermore, that never before has the teachers college assumed such importance as it has today and its importance will, doubtless, increase with time. The chaos into which our modern civilization has fallen has jolted us into the realization, now generally conceded, that world salvation rests in adequate education of all people. This can only be achieved through provision of the necessary schools staffed with well-prepared teachers. Since teachers colleges are important sources for school personnel, it follows that they are key factors in the making of a new world. The challenge is tremendous and inescap-

1 Paper presented at meeting of Teacher.Training Institutions Sections, A.C.R.L., June 18, 1948, at Atlantic City, N.J. able. They must now face the task of becoming the kinds of institutions which can supply the kinds of teachers needed to share so intimately and so extensively in creating world citizens who are also world-minded.

Sweeping and even radical changes will be required in many teachers colleges in order to meet the demands which will be made of them. Complacence and poverty can no longer be tolerated as terms characteristically applicable to these institutions. They must be supported as generously as are our laboratories for atomic research and experimentation if they are to assist effectively, even though indirectly, in preventing the creations of the laboratories from crashing about our ears.

As a pivotal point in the educational center, the library in the teachers college must reflect the metamorphosis which the institution, as a whole, is virtually obligated to promote and to sustain. It cannot continue to function according to traditional patterns if it is to maintain its traditional position of importance in the life of the institution.

Man does not learn by books alone in this day of multi-media communication. His ideas and the substance from which his thoughts are projected are gained from many sources. This is no less true for the teacher-in-training who, tomorrow, will be the teacher-in-practice. No effort should be spared nor should the necessary support be provided with reluctance for a task so important as that of insuring the optimum 
learning in a teacher-training program. This can be done only by making available in adequate quantity and variety the different materials of communication. This is the concern of the library. If it is to remain the source of instructional materials, it must become more than a "book house." It must continue to enlarge its book stock, but, in addition, it must build the needed collections of nonbook materials ${ }^{2}$ which can enrich the teaching procedure.

Obviously, the collections included in a "total library" are essential for two reasons and they must embrace materials of two types, in general. The collections, in the first instance, must supply the prospective teacher with the information, in whatever media, which will contribute to his education as a person and as a teacher and which will demonstrate to him the diversity of materials that may be employed in the teaching process. In the second place, they must include materials suited to his needs as an adult learner and those which are appropriate for use with children of varying ages and interests. Collections of broad scope are, therefore, indicated.

Due to active and passive resistance or to disinterest on the part of librarians and to indifference on the part of administrators, many libraries are not yet "total libraries." This is regrettable since it has, in general, been responsible for one of two results. Either the library has remained primarily a book center, or a separate center for housing and distribution of the nonbook materials has been established. In the latter case, the ensuing situation is neither logical nor economical. Furthermore, it may impose unnecessary inconvenience on the patron in general, and on the research student in particular.

2 The term "nonbook materials" is used in lieu of such terms as "audio-visual materials" or "audio-visual aids" since, strictly speaking, the latter terms do not exclude
books. The printed book is unquestionably visual.
There seems to be no defensible reason why book and nonbook materials of communication should be separated. In numerous instances, films, filmstrips, recordings, and books incorporate identical texts, as is true with some dramatic and other literary compositions. In subject areas, the ideas and concepts presented are similar or identical. Only the media through which they are communicated differ. To separate these materials because of their packaging seems as logical as would the establishment of separate stores to sell crackers contained in paper boxes, tin cans, or those wrapped in cellophane. The economic disadvantages to the institution are apparent since separate quarters, another administrator, and another staff are often involved in the divided arrangement. Finally, in a system which decentralizes and scatters materials that are closely related in subject content, the patron suffers. He is required, by such an organization, to consult separate indexes, separate staffs, and possibly to visit separate buildings in order to assemble materials or references involving related content. Such parallel administrative units which are created to perform the identical functions of assembling, organizing, housing, and distributing recorded communications constitute what is a false pattern and should not be encouraged or perpetuated.

Some recent trends have been encouraging to those who are committed to the idea of a coordinated materials center rather than one devoted exclusively to the products of the printing press. Most encouraging of all, perhaps, is the acceptance of the "total library" philosophy as indicated in the statement of "Minimum Standards for Accrediting Teachers Colleges and Normal Schools" which appeared in the TwentySixth Yearbook of the American Association of Teachers Colleges, 1947. Some excerpts from this statement will illustrate the posi- 
tion of the association. Under the subheading "The Relationship of the Library's Services to the Institution's Educational Program" appears the following: "The library should be able to: (a) supply needed books and other materials when they are needed. ..." etc.

Throughout the statement, provision for nonbook materials is made. Specific mention of the kinds of materials to which reference is made appears in the section which describes the library's program of services as follows,

The library of a teachers college should be one of the principal centers for instruction, study, research, and recreation, and its various services should facilitate these activities. Its program of services should be judged in terms of such items as: the availability of books and other materials ... etc., and the extent to which the library provides for the collection, housing, display, and easy use of such items as: uncataloged pamphlets, pictures, prints, and photographs; maps; phonograph records; slides and stereographs; microfilms; motion picture films; strip films; exhibits ... etc. Expanding college programs will add to such a list.

Time does not permit the numerous citations that might be made from the professional literature with respect to the "total library" philosophy which is becoming widely accepted. One other reference, however, seems particularly appropriate in this consideration of the responsibility of the teachers college library since the sponsoring institution is dedicated to the training of school personnel, including in many cases, school librarians. This is the statement with regard to the "Book Collection and Other Library Resources" which appears in School Libraries for Today and Tomorrow; Functions and Standards prepared by a committee of the American Library Association. The introductory paragraph under the subheading "Audio-Visual Aids" reads:
In addition to books, challenging new materials are becoming an important part of library resources. Some new audio-visual aids for learning are $16 \mathrm{~mm}$. films, filmstrips, slides, museum objects, radio programs, recordings, and transcriptions, as well as flat pictures, maps, and other nonbook materials which are essential in a good learning situation.

The inclusion of such provisions, in standards which affect teachers colleges and the school for which they train personnel, places more than a moral obligation upon these agencies to develop comprehensive collections. It only seems deplorable that coercive measures are necessary to induce a development which appears so logical and desirable. If the teachers college of tomorrow is to be the dynamic force in an evolving world civilization, which indeed it must be lest a titanic regression be invited, it must become the power that moves the frame. It must not continue to be the frame that moves only as the result of outside stimuli.

Recently, Dr. John R. Emens, president, Ball State Teachers College, made a statement of the library philosophy which obtains on the campus. A part of this statement reads as follows:

The philosophy that underlies the total library program at Ball State Teachers College-namely, that the library is an instructional service agency for all areas and departments-has made the library the distributing center for all types of instructional aids. All students, faculty members, supervising critic teachers, and others who are served by the library are able to obtain all materials of all kinds, both book and nonbook, through a coordinated library service. . . .

All prospective teachers and other students on the Ball State Teachers College campus should become competent in the utilization of all forms of teaching procedures, methods, and aids. ...

For a period of approximately nine years, the library at Ball State has served as a true center for recorded communications and other teaching aids. The decision to incorporate the nonbook materials with the 
books was based on the logical reasoning of the former librarian and the college administrative authorities that there was no justification for separating related materials designed to serve similar if not identical purposes. They recognized the fact that the packaging did not necessarily change the nature of the contents.

The development of this total library has progressed steadily if somewhat slowly. The war period retarded progress since materials and equipment were difficult and even impossible to obtain during those years. At the present time, the collections of nonbook materials contain over 55,000 separate items. Among these are approximately 400 motion picture films, 300 filmstrips, 250 nonmusical recordings and transcriptions, I 200 slides, 300 stereographs, 25,000 mounted pictures, 2000 pictorial post cards, and numerous maps, charts, posters, illustrated pamphlets, textiles, models, replicas, framed pictures, pottery, carvings, educational toys and games, and various other materials which are used in the process of teaching students to teach and to live.

Since storage facilities for many of these materials must be of a specialized and individualized nature, most of them are housed in a large room equipped for this purpose and known locally as the library teaching materials service. Adjoining this large room is one of the projection studios in which motion pictures, other materials requiring projection, and recordings are serviced for class or other groups. This and a second projection studio, both especially equipped for the purpose, are scheduled throughout the day and evening for groups or classes. In addition, many motion pictures, filmstrips, recordings, and slides are shown in the classrooms by student library staff operators.

A glance at the statistics on the use of these materials during the year $1946-47$ re- veals some interesting facts. A total of 1909 motion picture films were used on the campus. These were shown 2639 times; of this total, 848 titles were films rented from off-campus sources which represent I 285 showings. The known campus audience which was reached through these films totaled 95,558. Interesting to compare with this figure is that for the total campus circulation of books which was 137,071 .

Beside motion picture films, there were I I ,689 nonbook items which were borrowed from the library for use on-campus. These were distributed somewhat evenly among students and faculty. Included in this total were 44 different types of material. Those borrowed most frequently were pictorial illustrations of various kinds (folios, plates, mounted pictures, post cards, and posters) with a circulation of 5426; slides, including their study guides, with a circulation of 2348; educational games and toys with a circulation of $975 ; 435$ pamphlets; and 380 catalogs and periodicals dealing with nonbook materials. Other loans included 192 recordings and transcriptions, 182 filmstrips with their study guides, I 53 textiles, I I 2 charts, 99 maps and globes, 86 models, and $8 \mathrm{I}$ wall hangings. The figures indicate a use which is concentrated within a few groups of materials composed mainly of those which communicate ideas graphically (on film or other medium) or by audio means.

Both book and nonbook materials are used by faculty and students throughout the entire instructional program. Faculty members schedule most of the films which are used in connection with class presentations. Classes are brought to the library for films and for lectures on and demonstrations of the use of other materials appropriate for a particular purpose. Arrangements are often made for films, filmstrips, or recordings relative to class discussions to 
be presented in the classrooms. Displays of various materials are arranged for class and group use in the classrooms. Student teachers often use films and other materials during their teaching experience. In the process of planning their work, they spend considerable time with library reference assistants locating and examining materials suited to their needs.

The main card catalog in the library is a comprehensive catalog of campus holdings. It includes listings of both book and nonbook materials. For those interested only in locating nonbook materials, there is a divisional card catalog in the library teaching materials service in which duplicate cards are filed for all nonbook items cataloged. In cataloging the nonbook materials, there is a strong emphasis placed on subject entries although entries are made for all important names and titles connected with the work. All cards for book and nonbook materials are interfiled in the main catalog.

Due to difficulties in shifting many of the nonbook materials, only slides, maps, and stereographs are classified according to Dewey. The very full subject and other listings in the catalogs are the guides to the materials. The call numbers are composed of location symbols only. Each separate type of material is designated by an alphabetical symbol followed by the accession number which indicates the fixed location of any item among others of its kind.

A manual of complete routines governing the cataloging of each type of material has been prepared by the library technical service staff. This is used by staff members who catalog the materials and in the library science course in which the organization of nonbook materials is taught. This manual is revised from time to time and is not yet in final form. It is planned to duplicate it eventually for distribution to library science students and for others interested in it.
Costs of nonbook materials should not be considered in terms of book costs. Many of these materials are mass media which are used mainly with groups and although the unit costs may seem high, as in the case of films, the cost in terms of individuals reached may average a very low figure over a period of time.

Moreover, librarians and administrators should not make the mistake of thinking that a library which is to include all types of communicative materials can be built or maintained on the same budget which served to build a book collection. It follows, logically, that if a collection is to contain materials in addition to books, additional resources must be provided for both materials and staff.

At Ball State, it has been found that approximately 30 per cent has been added to the library budget for maintaining the nonbook service division. During the year 1946-47, 28 per cent of the total maintenance budget was spent for the nonbook service. The budget for the current year provides $\$ 43,895$ exclusive of salaries, student wages, and building maintenance. Of this amount, $\$ 13,125$, or 30 per cent, is earmarked for the nonbook service division. It should be emphasized that this is for maintenance alone. The establishment of such a division should involve a larger proportion of the budget for a few years.

An important consideration in building a budget for a nonbook division is that of equipment and equipment maintenance. Provision should be made for periodic replacement of equipment. In order to insure satisfactory performance and to avoid damage to materials, equipment should be serviced frequently. It is an economy, in the long run, to trade in pieces every few years on the latest models. This is essential, too, if students in methods classes and others, (Continued on page. 322) 
animal husbandry, and farm economics, is progressive in almost all its aspects and inescapably world wide. In both tempo and scope, it has become an implacable enemy of reference books.

This does not mean an end of agricultural reference books, but it does mean specialized and modest ones. It also means that an increased load must be placed on another element of our service. Old Varro, the Roman agricultural authority, divided the instruments of agriculture into the mute and the articulate. If he lacked a plow, or any mute instrument, I'm sure he would have had the digging done by the hands of his aritculate slaves. So today with the steady failing of organization in our research documentation, we must pass from hope of help in printed guides, to our reference and other librarians who as best they can must find what print exists to apply to our readers' problems. This, however, is a whole new subject and needs a paper at next year's meeting.

\section{Nonbook Materials in a Teachers College Library}

\section{(Continued from page 315)}

who are taught the use of various types of equipment, are to gain a knowledge of desirable equipment available on the market.

In conclusion, I should like to say that probably the outstanding characteristic of our modern civilization is the rapidity at which change takes place. As Dean Ralph Noyer of our college pointed out recently, there are students now enrolled in teachers colleges who will live to witness the beginning of the twenty-first century, barring atomic destruction or other catastrophe of equal magnitude. If the rate of change in all aspects of living is accelerated proportionately to that which we have experienced during the first half of the present century, these persons and those who follow must accept frequent and sudden adjustment as part of the usual pattern of living to an ever increasing degree. The implications of this prospect for education are clear. Preparation for living and working effectively and for meeting the problems of a civilization in a persistent state of flux will require every resource at our disposal if cultural degeneration is to be avoided.

Teachers must be among the best informed and the best prepared vanguard in the vital struggle with circumstantial forces. A knowledge of and the ability to use intelligently every existing form of communication and teaching aid are essential parts of their equipment. The library in a teachers college which does not provide the needs of its constituency must necessarily become relegated to that class of agency which first assumes a role of minor importance and eventually passes into oblivion. 